\title{
Second wave of the COVID-19 pandemic: D-dimer levels are not so high anymore
}

\author{
Angelo Porfidia ${ }^{1} \cdot$ Enrica Porceddu $^{1} \cdot$ Rosa Talerico $^{1} \cdot$ Massimo Montalto $^{1} \cdot$ Francesco Landi $^{1} \cdot$ Roberto Pola $^{1}(\mathbb{C}$
}

Accepted: 13 April 2021 / Published online: 22 April 2021

(c) The Author(s), under exclusive licence to Springer Science+Business Media, LLC, part of Springer Nature 2021

\section{Dear Editor,}

Italy was the first European country to be hit by the coronavirus disease 2019 (COVID-19) pandemic in the beginning of 2020. During that first wave, it was soon noticed that many patients hospitalized for COVID-19 had extremely high levels of D-dimer, with values often in the range of thousands and high incidence of venous thromboembolism (VTE) [1]. For instance, we reported that, among patients hospitalized for COVID-19 in the Internal Medicine wards of our University Hospital in Rome, Italy, during a random week of the month of April 2020, the mean D-dimer level was $4108 \pm 7098 \mathrm{ng} / \mathrm{ml}$ [2]. Very high levels of D-dimer have been consistently reported by many other authors in various countries [3]. Based on this, D-dimer has become the laboratory hallmark of COVID-19-induced coagulopathy and the biomarker used to discriminate between patients at high and low risk of thrombotic complications in both the international literature and the clinical practice [4].

Since October 2020, Italy is facing a severe second wave of the COVID-19 pandemic. However, we have been under the impression that, compared to the first phase, D-dimer levels are now substantially lower. To confirm this impression, we conducted a retrospective analysis comparing 247 consecutive patients hospitalized in dedicated Internal Medicine wards at our University Hospital during the first wave of the COVID-19 pandemic (between March and May 2020) and 142 consecutive patients hospitalized in the same Internal Medicine wards during the second wave of the COVID-19 pandemic (between October and December 2020). D-dimer levels were assessed by using a latex

Roberto Pola

roberto.pola@unicatt.it

1 Department of Medicine, Fondazione Policlinico Universitario A. Gemelli IRCCS, Università Cattolica del Sacro Cuore, 9th floor, C wing, room C907, L.go A. Gemelli 8, 00168 Rome, Italy agglutination test. We found that the mean D-dimer level during the first pandemic phase was $3585.0 \pm 7172.2 \mathrm{ng} / \mathrm{ml}$, while it was $1748.1 \pm 3417.5 \mathrm{ng} / \mathrm{ml}$ during the current second phase $(\mathrm{P}=0.02)$ (Table 1$)$.

Why is this happening? One possibility is that the patients that we are treating during the second pandemic wave in Italy are less severely ill than those that we saw during the first phase of the COVID-19 pandemic. However, this does not seem to be the case. Indeed, as shown in Table 1, patients in the second wave are older than those in the first wave and are more often affected by hypertension, diabetes, and ischemic cardiovascular diseases (including coronary artery disease, previous stroke, and peripheral artery disease). Also, the levels of the prototypical inflammatory marker C-reactive protein (CRP) are not different between the two groups $(93.2 \pm 77.6$ vs $74.1 \pm 67.4 \mathrm{mg} / \mathrm{l}, \mathrm{P}=0.07)$, while with cell count is higher among patients in the second pandemic wave $(6943.5 \pm 3187.4$ vs $8811.2 \pm 3767.4$ cells $/ \mathrm{mmc}$, $\mathrm{P}=0.001$ ). In addition, we have calculated that the mean quick COVID-19 severity index (qCSI), a score that predicts critical respiratory illness in patients admitted to the hospital with COVID-19 [5], is higher now than among patients hospitalized during the first wave of the pandemic $(4.4 \pm 4.3$ and $2.1 \pm 3.3$, respectively, $\mathrm{P}<0.001)$. Taken together, these data do not support the hypothesis that D-dimer levels are lower because patients are less severely ill.

Another possible explanation is that now many patients receive early treatment with anticoagulants and steroids at home, before being hospitalized. This might change D-dimer dynamics and affect serum levels at the time of hospital admission. Indeed, D-dimer is a plasmin-derived soluble degradation product of cross-linked fibrin and its generation requires the sequential activity of three enzymes, including thrombin being inactivated by the action of heparin bound to antithrombin [6]. Therefore, on one side, heparin administration may reduce $\mathrm{D}$-dimer production through thrombin inhibition and, on the other, steroid use could limit endothelial damage and the release of intrinsic pathway coagulation 
Table 1 Comparison between patients during the first and second pandemic wave

\begin{tabular}{|c|c|c|c|}
\hline Characteristics & $\begin{array}{l}\text { 1st pandemic wave } \\
(\mathrm{n}=247)\end{array}$ & $\begin{array}{l}\text { 2nd pandemic wave } \\
(\mathrm{n}=142)\end{array}$ & P-value \\
\hline \multicolumn{4}{|l|}{ Demographic and clinical characteristics } \\
\hline Mean age, years $\pm \mathrm{SD}$ & $65.3 \pm 15.4$ & $71.4 \pm 14.0$ & 0.47 \\
\hline Men, n (\%) & $160(65.0 \%)$ & $83(58.0 \%)$ & 0.21 \\
\hline Hypertension, n (\%) & $115(46.5 \%)$ & $88(61.9 \%)$ & 0.003 \\
\hline Diabetes, n (\%) & $32(12.9 \%)$ & $32(22.5 \%)$ & 0.01 \\
\hline Ischemic cardiovascular diseases, $\mathrm{n}(\%)$ & $29(11.7 \%)$ & $31(21.8 \%)$ & 0.007 \\
\hline VTE, n (\%) & $4(1.6 \%)$ & $3(2.1 \%)$ & 0.72 \\
\hline COPD, n (\%) & $20(8.0 \%)$ & $10(7.0 \%)$ & 0.70 \\
\hline \multicolumn{4}{|l|}{ Laboratory and clinical results during hospitalization } \\
\hline Mean D-dimers, $\mathrm{ng} / \mathrm{ml} \pm \mathrm{SD}$ & $3585.0 \pm 7172.2$ & $1748.1 \pm 3417.5$ & 0.02 \\
\hline Mean C-reactive protein, $\mathrm{mg} / \mathrm{L} \pm \mathrm{SD}$ & $93.2 \pm 77.6$ & $74.1 \pm 67.4$ & 0.07 \\
\hline Mean leukocytes, cell/mmc $\pm \mathrm{SD}$ & $6943.5 \pm 3187.4$ & $8811.2 \pm 3767.4$ & 0.001 \\
\hline Mean $\mathrm{PaO} 2 / \mathrm{FiO} 2$, ratio $\pm \mathrm{SD}$ & $292.2 \pm 84.6$ & $284.1 \pm 77.6$ & 0.16 \\
\hline Time from symptoms to D-dimer measurement, days $\pm \mathrm{SD}$ & $7.2 \pm 4.0$ & $4.9 \pm 4.2$ & $<0.001$ \\
\hline $\mathrm{qCSI}$, mean $\pm \mathrm{SD}$ & $2.1 \pm 3.3$ & $4.4 \pm 4.3$ & $<0.001$ \\
\hline Deaths, n $(\%)$ & $39(15.7 \%)$ & $20(14.0 \%)$ & 0.65 \\
\hline Hospital length in subject who died, days \pm SD & $14.5 \pm 11.4$ & $16.2 \pm 14.3$ & 0.30 \\
\hline \multicolumn{4}{|l|}{ Pre-admission therapy } \\
\hline Anticoagulant, $\mathrm{n}(\%)$ & $14(5.6 \%)$ & $60(42.2 \%)$ & $<0.00001$ \\
\hline Steroids, n (\%) & $7(2.8 \%)$ & $54(38.0 \%)$ & $<0.00001$ \\
\hline Anticoagulant AND steroids, $\mathrm{n}(\%)$ & $2(0.8 \%)$ & $31(21.8 \%)$ & $<0.00001$ \\
\hline Anticoagulant OR steroid, n (\%) & $19(7.7 \%)$ & $83(58.4 \%)$ & $<0.00001$ \\
\hline
\end{tabular}

factors. Although there is not a general consensus on the use of anticoagulants and steroids out of the hospital [7, 8], it is common knowledge that these medications are often prescribed to individuals with SARS-COV-2 infection by general practitioners and physicians working in the home-care system. As presented in Table 1, $42.2 \%$ of the patients that were hospitalized during the second wave of the COVID-19 pandemic had received some type of anticoagulant therapy at home, before being admitted to the hospital. There were also many patients that had received treatment with steroids at home (38.0\%). In total, the percentage of patients that had received either an anticoagulant or a steroid at home, before hospitalization, was $58.4 \%$. This is a relevant difference, compared to the first phase of the COVID-19 pandemic, when still there was great uncertainty about the appropriateness of the use of anticoagulants and steroids even in patients hospitalized for COVID-19. At that time, the use of such medications at home was virtually absent, or at least much lower than now. Obviously, it would be important to consider also the time between the onset of symptoms and hospitalization, because patients who stayed at home for a longer period of time before being hospitalized might have been exposed to an increased risk of VTE, due to reduced mobility and acute infection. Also, these patients might have received anticoagulants at home for a longer period of time, with an effect on the D-dimer levels measured at the time of hospitalization. Nonetheless, one could hypothesize that patients who were able to manage the disease at home for a long period of time had a milder form of the disease, compared to those who required prompt hospitalization. For all these reasons, it is difficult to determine the actual effect of home treatment on the levels of D-dimer that were measured at the time of hospital admission.

Our observation that D-dimer levels in patients hospitalized for COVID-19 are lower now than during the first wave of the pandemic may lead to interesting considerations. One is that there is a discrepancy between D-dimer levels and disease severity. Indeed, as shown in Table 1, patients hospitalized during the second wave of the pandemic had similar $\mathrm{PaO} 2 / \mathrm{FiO} 2$ ratio, similar mortality rate, and even higher qCSI, compared to patients hospitalized between March and May 2020. This might indicate that D-dimer is not a reliable prognostic marker of disease severity, as its levels do not correlate with the risk of developing critical respiratory illness, in contrast with the established notion that the degree of D-dimer elevation is associated with a greater likelihood of respiratory failure and mortality in COVID-19 patients. Another consideration is that lower D-dimer levels might facilitate the use of D-dimer as diagnostic marker of VTE. Indeed, the mean D-dimer values that we measured during 
the first wave of the pandemic were above the thresholds recently proposed to identify COVID-19 patients with VTE, while the mean values measured during the second wave are substantially below these thresholds $[9,10]$. Taken together, these findings suggest that, while D-dimer remains a powerful negative diagnostic and predictive marker, its thresholds for the management of COVID-19 are not yet established.

In conclusion, we report a significant reduction of D-dimer levels, when patients hospitalized during the second phase of the COVID-19 pandemic are compared to patients that were hospitalized in the beginning of 2020. Although the cause of this phenomenon remains to be elucidated, we believe that this finding deserves attention, in consideration of the important role that D-dimer has assumed as diagnostic and prognostic biomarker in patients affected by COVID- 19 .

\section{Declarations}

Conflict of interest The Authors have no conflict of interest to disclose that are relevant to the content of this article.

\section{References}

1. Porfidia A, Valeriani E, Pola R et al (2020) Venous thromboembolism in patients with COVID-19: systematic review and metaanalysis. Thromb Res 196:67-74
2. Santoliquido A, Porfidia A, Nesci A et al (2020) Incidence of deep vein thrombosis among non-ICU patients hospitalized for COVID-19 despite pharmacological thromboprophylaxis. J Thromb Haemost 18:2358-2363

3. Gungor B, Atici A, Baycan OF et al (2021) Elevated D-dimer levels on admission are associated with severity and increased risk of mortality in COVID-19: a systematic review and metaanalysis. Am J Emerg Med 39:173-179

4. Iba T, Levy JH, Levi M, Thachil J (2020) Coagulopathy in COVID-19. J Thromb Haemost 18:2103-2109

5. Haimovich AD, Ravindra NG, Stoytchev S et al (2020) Development and validation of the quick COVID-19 severity index: a prognostic tool for early clinical decompensation. Ann Emerg Med 76:442-453

6. Weitz JI, Fredenburgh JC, Eikelboom JW (2017) A test in context: D-Dimer. J Am Coll Cardiol 70:2411-2420

7. Piazza G, Morrow DA (2020) Diagnosis, management, and pathophysiology of arterial and venous thrombosis in COVID19. JAMA 324:2548-2549

8. Siemieniuk R, Rochwerg B, Agoritsas T et al (2020) A living WHO guideline on drugs for COVID-19. BMJ 370:m3379

9. Mouhat B, Besutti M, Bouiller K et al (2020) Elevated D-dimers and lack of anticoagulation predict PE in severe COVID-19 patients. Eur Respir J 56:2001811

10. Jevnikar M, Sanchez O, Chocron R et al (2021) Prevalence of pulmonary embolism in patients with COVID 19 at the time of hospital admission. Eur Respir. https://doi.org/10.1183/13993003. 00116-2021

Publisher's Note Springer Nature remains neutral with regard to jurisdictional claims in published maps and institutional affiliations. 